\title{
Disease Response Vendor Name
}

National Cancer Institute

\section{Source}

National Cancer Institute. Disease Response Vendor Name. NCI Thesaurus. Code C117396.

The literal identifier of the vendor or laboratory that performs a disease response assessment. 